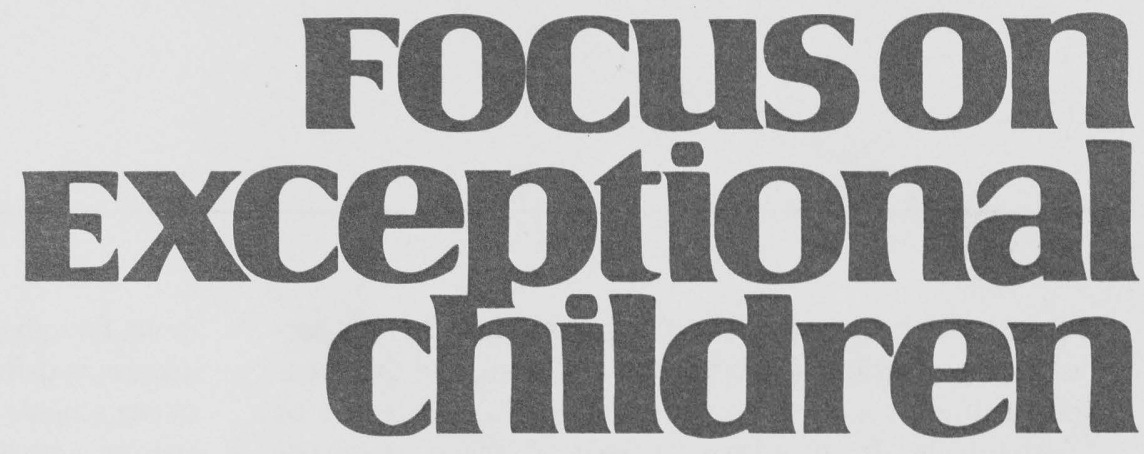

\title{
Managing Inclusive Instructional Settings: Technology, Cooperative Planning, and Team-based Organization
}

\author{
John Langone
}

As we move closer to the beginning of a new century, instructional options for students with disabilities are becoming more prevalent in classes frequented by their typical peers. Over the past 10 years, reform in education has stimulated a commitment by many general and special educators to teach learners with disabilities in natural educational environments. The commitment to teach students entirely in general education classes is by no means universal, and debates rage on concerning the appropriateness of such options for all learners with special needs (Cipani, 1995). The willingness, however, to determine if total inclusion is a viable option for students is now more prevalent than ever before.

From the inception of PL 94-142 in the mid 1970s to the current reauthorization of the Individuals with Disabilities Education Act (IDEA), the concept of least restrictive environment (LRE) has been the cornerstone for understanding the current move toward more inclusive environments for students with special needs. In the past, parents and professionals occasionally misinterpreted the philosophy of the LRE. Basically, living and learning in the least restrictive environment means that individuals with disabilities have the right to participate in environments as close to normal as possible. Each situation is determined by a student's strengths and weaknesses. Originally, the principle of least restrictive environment was developed to offset the practice of placing learners in self-contained settings when their needs did not dictate placement in those environments (Langone, 1990). In addition, the principle of LRE held that individuals in residential settings should have educational goals designed to assist them in moving to less restrictive settings as soon as possible.

The principle of least restrictive environment applies to all learners. For example, students with mild cognitive disabilities who have the skills to participate in general classes with support from special educators should be placed there fulltime. Similarly, learners with severe disabilities should not be placed in residential programs if they can benefit from being in public school classes. As a philosophy, least restrictive environment has emphasized the fluid nature of special education programs, and this philosophy can be considered the prelude to the current inclusive movement.

For many reasons, inclusive environments have become increasingly popular in school systems across the United States. Some of these reasons are supported by research, and others

John Langone is professor of Special Education at the University of Georgia, Athens. 
are supported by a deep sense of "what is right." Not all parents and professionals support full inclusion, and their reasons also are supported by research and a deep sense of "what is right." In any case, over the next decade, more special educators will participate in programs that offer either full inclusion for students with special needs or provide inclusion in general education at least part of the time (Cartledge \& Johnson, 1996). To get a better sense of what is required of teachers in inclusive programs, the following is a brief overview of certain events that have led to an increase of inclusionary practices.

\section{INCLUSIVE PROGRAM OPTIONS}

Students with special needs are still placed in many different program options ranging from less restrictive to more restrictive. Less restrictive models have a variety of names. More frequently, schools are using the term inclusion to describe placing students with special needs in classes with their typical

\section{Focuson
Exceptional children}

ISSN 0015-511X FOCUS ON EXCEPTIONAL CHILDREN (USPS 203-360) is published monthly except June, July, and August as a service to teachers, special educators, curriculum specialists, administrators, and those concerned with the special education of exceptional children. This publication is annotated and indexed by the ERIC Clearinghouse on Handicapped and Gifted Children for publication in the monthly Current Index to Journals in Education (CIJE) and the quarterly index, Exceptional Children Education Resources (ECER). The full text of Focus on Exceptional Children is also available in the electronic versions of the Education Index. It is also available in microfilm from Xerox University Microfilms, Ann Arbor, MI. Subscription rates: Individual, $\$ 30$ per year; institutions, $\$ 40$ per year. Copyright (C) 1998, Love Publishing Company. All rights reserved. Reproduction in whole or part without written permission is prohibited. Printed in the United States of America. Periodicals postage is paid at Denver, Colorado. POSTMASTER: Send address changes to:

$$
\begin{gathered}
\text { Love Publishing Company } \\
\text { Executive and Editorial Office } \\
\text { P.O. Box } 22353 \\
\text { Denver, Colorado } 80222 \\
\text { Telephone (303) } 757-2579
\end{gathered}
$$

Edward L. Meyen University of Kansas

Richard J. Whelan

University of Kansas Medical Center
Stanley F. Love

Publisher
Glenn A. Vergason

Georgia State University

Thomas Love

Managing Editor peers for either most or part of the school day. In practice, inclusion is defined differently depending on the school district. Some schools refer to inclusion in a broad sense, allowing all persons with disabilities the right to participate with their general-education peers to the maximum extent possible (full inclusion). Other programs view inclusion as more restricted, placing students with disabilities in general education only part of the day (two or three periods or segments a day).

As the field of special education moves toward the end of this century, a renewed interest in closely inspecting the curriculum, particularly regarding inclusive settings (Rekkas, 1997). Professionals such as Polloway and Smith (1983) have called for a move away from the "narrow focus on academic and remedial concerns" (p. 157). This call is as critical today as when the authors first published their ideas. The alternative, then, is to develop a curriculum that is "community-valid." Community-valid skills are those that allow students to learn and practice skills applicable to community life. For example, a student assigned to a U. S. government class might be taught to call the local office of the senator representing the district to request assistance in obtaining information about changes in Social Security benefits.

\section{HISTORICAL DEVELOPMENTS LEADING TO INCLUSION}

One reason that has led many to call for more inclusive options for students with special needs is the past effects of educational options-or what has been called the continuum of services-for those learners. Educational options for students in special education historically have been static, and to some extent this situation still exists in some school systems. Once a learner is placed, there generally is little change from one placement option to another. Because movement across placement options within special education also can be difficult, rigidity in placement options is found within special education programs as well. For instance, learners who have been classified as having moderate intellectual disabilities may have little chance of being exposed to program options for students with mild intellectual disabilities, even if these options are demonstrated to be appropriate.

The principle of least restrictive environment highlights that student and family needs are continually changing, and with those changes comes the need to modify program options (McNulty, Connolly, Wilson, \& Brewer, 1996). Program goals should be designed to move learners on a continuum toward less restrictive environments. In reality, this has not been the case for many students with special needs and their families. 
An important component of the least restrictive environment is the principle of individualization. Individualization means that programs are based upon analysis of a learner's unique needs. As these principles become more commonplace, the emphasis should shift from the categorical label of students to their individual strengths and weaknesses. At present, the tendency is still to place learners according to the category of disability (e.g., LD, BD, MH).

The regular education initiative (REI) was a movement within the field of special education that preceded the inclusion movement, proposing that regular and special education be merged into one delivery system (Davis, 1989; Marozas \& May, 1988). The various options that REI supporters presented can be placed on a continuum ranging from fairly drastic measures of abolishing special education (Stainback \& Stainback, 1984) to more moderate measures of developing an equal partnership between regular (general) and special education (Reynolds, Wang, \& Walberg, 1987). Proponents of the REI included students with mild handicaps (e.g., MIMH, LD, and BD) and learners who were not targeted for special education but who had received some type of service (e.g., Chapter I reading programs).

In 1986, Madaline Will, the Secretary of Education, outlined what she saw as the limitation of special, remedial, and compensatory programs that pulled students out of regular classrooms to provide them with services designed to help them succeed in the so-called mainstream of the school system. She believed, as did other proponents of the REI, that special programs had failed in helping learners achieve their potential (Heller, Holtzman, \& Messick, 1982; Reynolds et al., 1987). Inconsistencies of labeling and classification systems were seen as reasons why these students were segregated and would ultimately become the outcasts of school systems. These professionals also supported the notion that all students with learning problems require the same type of help. They believed that the forced dichotomy of special and regular education created an unnecessary rivalry that hindered delivery of the best instruction to the very students who needed it most.

Proponents of the REI believe that too many students are being identified for special programs when they could be served adequately in general education classes with in-class support (Kauffman, Gerber, \& Semmel, 1988). Proponents point to evidence they believe supports new models of instruction for students with learning problems in general education classrooms (Hallahan, Keller, McKinney, Lloyd, \& Bryan, 1988; Wang \& Walberg, 1988).

Reynolds and his colleagues, suggested a heterogeneous grouping approach that would include curriculum-based identification systems and the Adaptive Learning Environments
Model (ALEM) (Wang, 1980). The ALEM model sets forth five strategies designed to adapt instruction to any student:

1. A hierarchically organized curriculum emphasizing the instruction of basic skills

2. Flexible learning environments

3. Classroom management programs that allow for a blend of diagnostic/prescriptive and exploratory activities

4. Cross-age programs that group learners' movement between teams of teachers based on their progress

5. Extensive family participation

Adoption of the ALEM program would restructure the entire school curriculum by arranging basic skills into hierarchical units. When students master one unit, they move on to the next higher one. The school essentially becomes ungraded, and students move through the system at their own speed. There would be no labeling. Students with significant learning problems would receive help based on their level of functioning in the units of instruction, not according to a categorical label.

ALEM seems to be a logical, commonsense approach with several points of merit. During the early part of this decade, it was popular among some educators who rallied around it as a viable alternative to the separation of special and general education. Some professionals, however, have urged caution in adopting the REI too quickly because of the lack of empirical evidence that it is as successful as its developers claim (Fuchs \& Fuchs, 1988a, 1988b).

With the call for eliminating existing special education programs in the late 1980s came a barrage of literature that questioned the validity of the REI (e.g., Braaten et al., 1988; Bryan, Bay, \& Donahue, 1988; Fuchs \& Fuchs, 1988a, 1988b; Hallahan et al., 1988; Kauffman, Gerber, \& Semmel, 1988; Keogh, 1988). For example, Kauffman and colleagues (1988) argued that two of the assumptions of the REI-the overidentification of students and the failure of the schools to meet their needsare untrue. They demonstrated that since 1986 the percentage of the student population receiving special education services has declined. According to these researchers, blaming teachers for the failure of all students is too simplistic and does not adequately explain the complex interaction between teachers and students with significant learning problems.

Hallahan and his colleagues (1988) looked at the REI from a research perspective and found its basis weak. They argued that the efficacy studies used by the REI proponents to prove the ineffectiveness of special education are flawed methodologically and have yielded mixed results. The results of these studies have provided little evidence that more intensive placements such as special education classes should be abolished. In an intensive critique of the ALEM research literature, Fuchs and 
Fuchs (1988) found enough methodological and analytical flaws to question whether this instructional approach has met its basic goals. Keogh (1988) raised an interesting set of concerns regarding the claims that the REI is a logical and commonsense approach. She questioned whether it is logical to assume that general educators can take over the program of students they already have failed to teach. In addition, she found that few, if any, of the proponents of the REI are general educators.

From the REI movement grew a reform effort that called for elimination of special education and full inclusion for all students with disabilities in general education classes. Most professionals and parents agree that, though increasing integration of individuals with disabilities in the general population is important, full inclusion into general education for all students with disabilities may be counterproductive (e.g., Jenkins, Pious, \& Jewell,1990; Fuchs \& Fuchs, 1994). As with many of the great debates in education, neither side of the REI/inclusion debate is right or wrong, and both sides have merit. Reynolds (1988), a proponent of the REI, has admitted to the need for "very careful reflections" concerning reforms of special education (p. 355). The field should not remain stagnant, because this will do little good for the students who need the best services. Taking an all-or-nothing stance either for or against REI/inclusion will not help students with special needs (Rock, Rosenberg, \& Carran, 1995; Zigmond \& Baker, 1996). Instead, special and general educators should focus on two main issues: identifying the best methods to teach learners based on their abilities and determining the best methods for working together as professionals to best meet the needs of all learners.

\section{MANAGING INCLUSIVE SETTINGS}

The most basic ingredient required for successful inclusion programs is the need for general and special educators to work together as equal partners in teams that solve problems, develop innovative program options and curriculum, and implement instruction to both students with and without disabilities (Williams \& Fox, 1996).

\section{Successful Collaboration and Quality Inclusion}

As we move into the next century, the roles of teachers will shift dramatically. Teachers will have to "wear a number of hats" to be successful in helping students gain the skills necessary for becoming independent and productive members of society. At the present, teachers from general and special education perform many duties. Completing the number and variety of these tasks places a burden of time on teachers that may cause some to lose sight of the existing continuum of services available from preschool to postsecondary and the need to make transitions across this range. When this happens, learners may lose out because they may not be properly prepared to meet the challenges presented in new situations. For example, learners with special needs entering a secondary program having not received instruction in career awareness and basic prevocational skills at the elementary and middle school levels may be disadvantaged in a program designed to instruct them in independent living, vocational skills, and general academics. Teacher teams (both from general and special education) need to be in continuous contact across grade levels (Cook \& Friend, 1996).

Initially, teacher teams should become thoroughly acquainted with professionals from all other grade levels where students will come from or move toward. For example, elementary teachers working as teams in inclusive environments should visit the classrooms of both preschool and secondary programs in their catchment area. Visiting those classes allow teachers to observe teaching techniques and materials and have the opportunity to coordinate program objectives in a scopeand-sequence fashion across different levels. This allows professionals team-teaching in inclusive programs to know what skills the students are working on at the various points in their programs (Eichinger \& Woltman, 1993). This strategy becomes important for special educators because these professionals may not have the extensive training in academic subject areas that is afforded to their general education team members. Also, increased teacher contact can lead to more coordinated assessment methods. When teachers across grade levels have been communicating regularly, learners entering a new program should not arrive without adequate support data.

Unfortunately, no matter the good intentions or how much teachers prepare the stress of working together as an inclusive team can become great, resulting in premature burnout for general and special educators alike (Frank \& McKenzie, 1993). For example, Farber (1991) discovered that both role conflict and role ambiguity can cause teachers to exhibit behaviors consistent with burnout. Role conflict occurs when teachers perceive that the demands of the job are inappropiate and cannot be accomplished within the given time constraints (Villa, Thousand, Meyers, \& Nevin, 1996). Role ambiguity results when teachers' rights, responsibilities, and status are unclear (Scruggs \& Mastropieri, 1996). Role conflict and ambiguity also can occur when teachers are placed in teaming situations without proper training in collaboration (Pugach \& Johnson, 1995).

Experts have posited several suggestions for collaboration techniques that should be incorporated in any inclusive teamteaching situation (Fisher, Schumaker, \& Deshler, 1996; Pu- 
gach \& Johnson, 1995; Voltz, Elliott, \& Cobb, 1994). First, school administrators need to assist teachers by providing them with clear guidelines as to what is expected of them or actually lead them in developing a workable plan that spells out the roles and responsibilities of each professional. Also, choosing teachers carefully prior to placing them in cooperative teams is an important variable that may reduce stress and burnout. Teachers should not be chosen randomly, nor should only new teachers be chosen for inclusive programs (Voltz et al., 1994). Peer-support groups consisting of both seasoned and newer teachers can be of great assistance to the inclusive teams (Pugach \& Johnson, 1995).

A truly collaborative team consists of two or more individuals who are equal in status and decision-making capabilities. In the case of an inclusive team composed of a general educator and a special educator, both professionals come to the classroom with identifiable strengths and weaknesses; therefore, both teachers can provide each other with useful strategies for instructing learners (Nolet \& Tindal, 1996). One way to accomplish this is to regularly schedule time to model instructional techniques (for each other or for other teachers) targeted for use with specific learners (e.g., the special educator's demonstrating a behavior-management technique or the general educator's presenting a reading strategy.

Another strategy for inclusion teams is to start a school newsletter for teachers. The newsletter can highlight successful attempts and ideas the team develops. Also, the inclusion team can make available an "idea box" of instructional strategies that others can use with students who may be exhibiting learning problems.

One goal of an inclusive team is to develop innovative instructional techniques that can be used with students who have disabilities while they are in the general classroom. Programs that use peer tutors and volunteers are examples of how teachers can increase the efficiency of instructional interventions.

Special and general educators alike must develop a plan designed to increase and maintain quality contacts with each other. Special educators can assist their colleagues in understanding the principles of curriculum modification - the need to identify specific content that is appropriate for a given learner. This model is significantly different from one in which teachers assume that learners must be exposed to everything in, say, a certain chapter in an earth science textbook. As a team, both teachers work toward choosing only the curricular objectives that are appropriate for the student.

The inclusive team can work to develop innovative program strategies in several ways (Villa, Thousand, \& Chapple, 1996). For example, the team can develop and implement communitybased activities that complement the more traditional class- room-based activities. The team might choose to teach earth science material via lecture and slide presentation and then complement this work by leading the students in a community project to retard soil erosion.

Because general educators are often consumed with large class loads and other responsibilities, special educators may need to take the initiative to increase and maintain high-quality contacts with general educators. Special educators should spend considerable time assisting and forging networks with their general education counterparts (Warger \& Pugach, 1996). For example, when beginning inclusion programs, special education teachers might consider identifying three or four general educators per month as people to get to know, through afternoon coffee sessions when they share ideas and talk about each others' programs.

\section{Physical Management of the Inclusive Setting}

Inclusive instructional settings can be located anywhere teachers decide learning is to take place. Most often, professional teaching occurs in classrooms. The concept of physical management of the inclusive setting has expanded into recognizing community locales as appropriate for teaching academic and social skills (Langone, 1996).

Arranging the physical environment to facilitate learning is important in developing successful inclusive programs. It goes beyond moving desks and chairs. Other considerations for designing an efficient learning environment include scheduling, developing group and individual activities, utilizing equipment and technology, and developing learning centers.

\section{Arranging the Physical Environment}

When arranging the physical environment of the classroom, the inclusive team should develop an overall plan (including diagrams), enabling a maximum use of space while keeping materials centralized, thus minimizing teacher movement. This becomes critical when instructional teams share space (Stainback \& Stainback, 1996). Teachers waste valuable instructional time when they have to stop lessons to retrieve materials in another part of the room. This situation also affects the other member of the inclusive team and the students they are teaching. Teachers should arrange the classroom in relation to the room's fixed features (doors, windows, closets), functional relationships among areas (study sections away from activities that produce higher noise levels), and primary pathways (efficient planning of student traffic routes).

The fixed features of a room become important when considering the requirements of specific activities. For example, an area of the classroom designed for teaching reading and written 
language skills should be near a computer and projection device. Similarly, the section for teaching science or cooking should be located in an area near a sink and water and cabinets for storing materials.

Arranging centers in relation to their functional characteristics is another important consideration. High rates of activity (such as a group math lesson) versus low rates of activity (an individual reading center) should be separated as far as possible. Centers that require sharing materials, such as a library center and study carrels, should be located close together. Planning efficient traffic patterns can save the inclusive team and the students valuable time and steps. For example, an activity requiring students to leave the room at varying intervals to retrieve water from the hallway lavatories might be located near the class entrance. This eliminates the need for students to move through other activities to reach the door. Activities can also be located so each inclusive team member in charge of a number of duties can easily manage those areas without crisscrossing the room and disturbing each other.

Various learning centers in the room should be located to facilitate orderly movement. To maintain order, teachers should not misinterpret this goal and structure classrooms in traditional ways that discourage student movement. The trend toward cooperative learning requires that students be allowed to work together to solve problems and complete projects. Classrooms, therefore, should be designed to teach and then allow maximum freedom and responsibility on the part of the students.

Classrooms should be set up to help the inclusive team scan the class with maximum efficiency. Teachers must have an unobstructed view of all areas of the room at any given time and be able to see each other so they can send visual cues that coordinate smooth transitions between activities. The ability to scan the classroom also helps facilitate behavior management. For example, teachers can help students learn to react to eye contact as a reminder to return to a task. Among the reasons for maintaining close visual contact with students, the most important is safety. Managing the instructional space by using visual scanning becomes critical as more inclusive programs move to a cooperative learning model wherein students work in instructional teams.

\section{Scheduling}

Developing an efficient activity schedule is a valuable skill for teachers. Downtime in the classroom can be a chief contributor to poorly managed inclusive programs. (Downtime refers to times of little or no instruction, students do not know what to do or what comes next). Teachers working in an inclusion model must consider the length of lessons, times of day more appropriate for teaching specific skills, and time blocks for individualized instruction as well as group instruction.

Time schedules can be used as learning tools as well as organizational aids. For example, the team may begin by scheduling daily activities consistently so students with and without disabilities can both benefit from the support of a structured environment. Activities do not always come in neatly arranged time blocks though. As students become more comfortable in working within cooperative learning groups in inclusive classrooms, teachers should plan deliberate changes in the schedule, thereby promoting flexibility in the students. If schedules are disorganized, students are in a continual state of confusion. Through carefully planned change, students can learn to deal appropriately with sudden alterations in schedules.

\section{Cooperative Learning Groups}

Grouping learners is an important part of scheduling (Vaughn, Bos, \& Schumm, 1997). The first step in grouping requires physically managing a given number of students. Teachers can divide the number of students in the class during a session by the total number of instructional personnel (teachers, paraprofessionals, peer tutors). This calculation gives the teacher the ratio of students to instructors. For example, if a classroom has 15 general education students and six students with disabilities from 10 a.m. until 11 a.m. with the inclusive team (two teachers) plus one paraprofessional, the ratio is 7 to 1 .

By viewing class sizes and composition in this manner, the inclusive team can better schedule activities in cooperative learning groups that are more easily managed with the addition of students who have special needs. In the scenario above, the six students with disabilities can be divided equally across three groups. Each teacher (general educator, special educator, and paraprofessional) will have a group of seven students (five general education and with special needs). Of course, the group numbers do not have to be equal at all times, but using this simple formula helps keep groups managable and allows for the development of innovative cooperative learning activities.

Programming for the individual does not eliminate group instruction (Stainback, Stainback, \& Stefanich, 1996). To develop true cooperative learning groups in which students with special needs become valued members, teachers should consider moving beyond grouping by ability and consider grouping according to the complementary skills of the learners. Small-group instruction can be implemented in one of two ways, depending on the activity. First, an activity may require that each group member complete a task that contributes to a total group product. For example, a group of students with special needs along with their typical peers can work together to complete a community-based cost-comparison activity in local retail establishments. Each 
student is assigned to identify the prices of certain items that the group will collate and analyze.

The second method of grouping involves meeting the needs of individual students within the confines of a group, where what the learners share in common are the subject and physical proximity (Stainback \& Stainback, 1992). For example, a group of four students may be working with the teacher on computation objectives. The learners may be at varying levels, requiring the teacher to spend small amounts of time individually directing each student. The primary concern is that the teacher arrange the physical space for delivering prompts/cues and reinforcers. This arrangement may be advantageous because the teacher can instruct and direct more learners simultaneously while allowing them to work at their own levels. Members of inclusive teams are encouraged to seek out helpful resources (e.g., Falvey, 1995; Stainback \& Stainback, 1992, 1996).

Commercially produced materials can also be helpful in deciding on how to group learners. A reading program that allows the teacher to work with a diverse group of students may be efficient because the teacher can increase the size of the group. Students with special needs generally have several deficit areas relating to academic skills, and high-quality commercially produced programs can be invaluable for teaching groups of students who need to learn similar, but not exactly the same, sets of skills.

Individualized instruction for students with special needs and for others in the class will still be needed for small portions of the day. Both members of the inclusive team should share these times equally to avoid the perception that the special educator works only with the students who have special needs.

\section{Inclusive Learning Centers}

Audiovisual equipment, microcomputers, and other instructional aids can be highly effective with all learners in the inclusive classroom. Commercial catalogs are one source for identifying these resources. Exhibits at professional conventions are another resource. Learners with special needs who are included in general education classes have a variety of instructional needs, and matching the appropriate equipment to those needs is important. Learning centers are often built around individual themes that can become the focal point for developing cooperative learning groups that include students with and without disabilities. A classroom may be equipped with centers dealing with subjects such as career education, science, prevocational skills, mathematics, reading, and self-care skills. These centers can be the focal point for presenting student groups with problems to solve under the guidance of one of the instructors from the inclusive team. For example, in an ongoing activity a group of fourth-grade students that includes students with and without disabilities might be tracking the fuel usage of the buses that service their school. Their daily tasks for the group are to check the buses when they arrive each morning, log the mileage, check the bus log for fuel used, and calculate the gas mileage of the bus. The learning center in which they work focuses on the functional applications of arithmetic skills.

\section{Inclusive Learning in the Community}

The psychological construct of situated cognition continues to receive considerable attention in the literature. For example, Brown, Collins, \& Duguid (1989) and Lave (1988) argue that learning should take place in realistic settings and under the guidance of "experts" who can provide learners with the knowledge to solve problems. In addition, these experts can provide the cultural indoctrination necessary to be successful in certain environments. These professionals view situated cognition as the application of knowledge and ideas to problems encountered in realistic environments and faced by people in their everyday life. Situated cognition contrasts the more typical method of teaching, in which learners acquire knowledge and meaning through abstract activities, memorized for later retrieval (Brown, Collins, \& Duquid, 1989; Young, 1993).

Situated learning describes the application of the situated cognition theory wherein students solve problems in everyday settings and in realistic contexts. The students learn by interacting with the environment under the guidance of teachers who facilitate learning (Griffin, 1995). Instructional strategies of situated learning rely on the use of experienced individuals who help students gain meaning about what they learn. These strategies are directly opposed to the instructional method of having learners memorize information for later retrieval.

Professionals who recommend situated cognition and learning rely heavily on Whitehead's (1929) discussion of inert knowledge as their basis of support (Cognition and Technology Group at Vanderbilt [CTGV], 1990; CTGV, 1993; Hedberg \& Alexander, 1994). Whitehead's use of the term inert knowledge focused on the learner's ability to store knowledge and recall it upon demand and also focused on their inability to use the knowledge to solve complex problems faced in everyday life (CTGV, 1990). Cognitive theorists believe that our current approach to education presents information to learners that, at best, proliferates the spread of inert knowledge (Brown, Collins, \& Duquid, 1989; Tripp, 1993).

Community-based instruction has long been regarded as an effective means for teaching students with disabilities the skills they need to make successful transitions in all aspects 
of life (Langone, 1990; McDonnell, Hardman, Hightower, Keifer-O' Donnell, \& Drew, 1993; Snell \& Browder, 1986). Community-based instructional programs are more developed for learners who have moderate intellectual disabilities and have, over the past five years, gained popularity for use with students who have more severe impairments (Hughes \& Agran, 1993; Wolfe, 1994). For students with mild intellectual disabilities, however, practitioners have not widely embraced the move to a curriculum that is community-referenced (Shriner, 1994). This trend in programming may be one variable that has resulted in less than successful transitions for these learners (Danielson \& Malouf, 1994; Edgar, 1987).

Community-based instruction can be considered situated learning and, therefore, the practical application of situated cognition. These activities can be beneficial in helping students with special needs acquire and use academic, vocational, and social skills. Learning these skills in community environments along with their peers from general education can enhance their understanding and generalization of these skills to everyday life. In the future inclusive teams may have more opportunities to develop and implement innovative situated learning activities in community environments.

As with classroom activities, when designing communitybased activities, teachers should consider the need for efficient scheduling and grouping of students. Scheduling problems can be worked out in conjunction with the administration. One solution would be to have one member of the inclusive team take a mixed group of students to a community site while the other team member conducts classroom-based activities with the remainder of the class. A well designed schedule is vital. Team members should set the schedules so the two have equal time in community environments (general educator one trip, special educator the next, and so on). Teachers need to be able to schedule frequent trips to the community with small groups while scheduling the remainder of the class in school-based activities (Janney, Snell, Beers, \& Raynes, 1995).

Scheduling the assistance of more able learners to assist the less able ones can also provide valuable help. Having teams of students work on problems or practice learned skills involves careful planning and matching of group members. As mentioned, carefully arranging the teaching environment (classroom, community work sites, and so on) increases the probability that students will learn. All space in the classroom should be used efficiently, and traffic patterns should be considered that allow freedom of movement to all areas. In addition, equipment and furniture should be arranged to allow observation of students from any point in the room.

\section{PROFESSIONAL COMPETENCIES FOR THE INCLUSIVE SETTING}

When teachers from different disciplines gather for crosstraining workshops, special educators at times have difficulty describing their specialty areas to others. General education teachers usually find this easier because most specialize in one or two content areas, such as reading, arithmetic, and science. Special educators are not always specialists in subject areas, and their skills and competencies are much more ambiguous.

Many special education teachers are proficient in three broad competency areas: (a) assessment and diagnosis, (b) curriculum development and modification, and (c) applied behavior analysis. Special educators should be able to use a variety of assessment tools to pinpoint students' strengths and weaknesses. Special educators also should be proficient in skills related to designing instruction based on student need. They should be capable of breaking down instruction into component parts, and also be expert in monitoring students' progress.

Finally, teachers should develop competencies involving behaviorally oriented instructional programs. This system allows teachers to define target behaviors precisely, conduct frequent and accurate measurements of defined behaviors, apply instructional procedures or materials designed to change students' behavior, measure change, and revise the program when necessary.

The ability to describe these competencies to other teachers is a good starting point for establishing cooperative relationships. For example, a general educator teaching a student with learning disabilities may need help in identifying the learner's academic strengths and weaknesses and matching a reading curriculum to those needs. The general educator provides the content expertise while the special educator provides the competencies of curriculum-based assessment and curriculum modification.

Another teacher competency that seems to be vital to the success of an inclusive program is the ability to use and schedule paraprofessionals and volunteers. With the additional duties inherent in combining students with and without special needs, the need for additional hands becomes critical. Before teachers can bring skills and knowledge to a team effort, they must first have a strong grasp of what they can and cannot do.

\section{Managing Instructional Personnel in the Inclusive Setting}

A problem that inclusive teams face is the need for additional classroom personnel. Often, funds for hiring additional staff are not available; therefore, more efficient use of existing personnel 
may be the best long-term solution. Using instructional support personnel efficiently requires clearly stated objectives for what the assistants are to accomplish. This management strategy begins with a written plan, developed by both members of the inclusive team, for each individual providing instruction for learners. This plan should be developed in a combined effort between the inclusive team and the assistants, allowing the instructional assistants an opportunity to provide input into the objectives.

The inclusion team sometimes provides assistants with only verbal instructions, assuming that they can follow through with the task. In some cases, however, the team may have more success using techniques such as modeling and prompts to demonstrate what they want the assistants to do. Observing instructional assistants can provide information for helping them to improve their skills.

Teachers may choose additional techniques such as selfcharting and public posting for managing the effectiveness of other instructional personnel. Various schedules of reinforcement are other important considerations for managing instructional assistants. The inclusive team may have more success at improving the effectiveness of their assistants if they provide them with frequent reinforcement and feedback concerning the quality of their work.

Scheduling frequent staff discussions is important in managing other classroom personnel. A 15-minute daily meeting after school to review the day's occurrences is often all the time that is needed to review and improve instruction. Handling problems is often easier when they are addressed as quickly as possible. Instead of blaming the instructional assistant for problems when they occur, the more productive strategy for the inclusive team teachers is to analyze what they can do to help the instructional assistants improve their work.

\section{Teacher Aides and Paraprofessionals}

Many teachers of learners with special needs have an aide of some type, ranging from a full-time assistant to varying levels of part-time help. Paraprofessionals-who may have degrees from community colleges or technical schools - can accomplish a variety of tasks that support the special educator, including managing students, providing basic instruction, and acting as members of the educational team. Paraprofessionals and teacher aides can be invaluable, and the inclusion team should guard them from being underused or inappropriately assigned tasks that lessen their effectiveness and efficiency. Both teachers of the inclusion team can avoid problems by precisely defining the roles of instructional assistants.

An important factor in establishing a good working relationship with instructional assistants is the ability to establish rap- port on a personal level and to feel comfortable with the individual. The inclusion team should participate in choosing an aide, and the teachers should establish a good working rapport on the first meeting day. The inclusion team should establish that the instructional assistants are a significant part of the educational team, with the stipulation that they must not take independent action and make decisions without the teachers' knowledge.

Instructional assistants can become effective instructors when the inclusion team trains them in appropriate classroom procedures. Brief training programs and periodic review sessions can assist other classroom personnel in learning the skills needed to observe student behavior consistently. The team might consider developing a training manual that explains how to deal with specific behaviors and implement specific classroom procedures. This technique can save lengthy discussions while providing the assistant with a guide for times when the team is unavailable for help. The manual can be more useful to assistants by including snapshots or drawings that depict the teaching technique being explained.

Assistants may be more willing to implement programs if they are included in the planning (Hart, 1981). Short daily meetings between the inclusion team and assistants provide a forum for correcting problems and sharing ideas. These meetings should foster dialogue between the team and the assistants and not be a one-sided conversation presenting all of the teachers' ideas. In addition, the inclusion team should develop daily schedules for the assistants and post them where the assistants can refer to their responsibilities frequently.

Volunteers are an often overlooked source of classroom assistance that can provide an inclusion team with a wealth of instructional talent. Volunteers will become more valuable as additional inclusion options emerge. Developing a good volunteer program involves careful planning and scheduling. One example of the effectiveness of volunteers becomes evident when the inclusion team wishes to implement a behavior analysis program. When the teachers and instructional assistants are busy with groups of learners, volunteers can be used as independent observers to record the on-task behaviors of students completing independent assignments. In this example, a volunteer parent might assist teachers by monitoring the behavior of target learners. This short-term program may last only 2 or 3 weeks, allowing the teacher time to evaluate a number of interventions for increasing more productive independent work.

Parents and other volunteers also can be of immense help in performing a wide variety of tasks that will become commonplace in inclusion programs. Helping students chart data for self-management programs and escorting learners on community instruction trips are additional roles for volunteers. When 
the inclusion team uses parents as classroom assistants, the benefits are evident. Communication between the school and the home is likely to improve when parents feel they are part of the process. Also, parents may learn by observing teachers' preferred teaching practices that can be applied at home. Ultimately, parents may become comfortable with the inclusion team and provide valuable input into the program.

Many other volunteer resources are available in communities as classroom support. Members of church groups, service organizations, and specific community members known to the teachers can act as instructional assistants. Volunteers can provide services aside from classroom assistance - such as local retailers' allowing learners to practice consumer skills in their store. Other examples of persons who can provide valuable services are salespersons, personnel managers, and bus drivers. Help is available to institute a number of innovative program options if teachers are willing to seek it out and provide the necessary leadership and coordination skills.

\section{University and College Instructional Assistants}

For inclusion teams that have access to student teachers and practicum students, these people can be a great asset by becoming an "extra pair of hands," providing support to students that might otherwise be unavailable. Scheduling a student teacher's duties should reflect a gradual increase in responsibility, moving from small groups to eventually doing programming for the entire class.

Initially, teachers should make a list of the skills they would like the student teachers to gain during the internship. Likewise, the inclusion team should have the student teachers list the skills they would like to attain during their internship. Together the teachers and interns can translate both lists into behavioral objectives to be completed by the end of the quarter or semester. As with other assistants and volunteers, the inclusion team should schedule short daily sessions with the student teachers to discuss problems or concerns, as well as allow the intems to contribute ideas to program development.

\section{Additional Management Strategies}

Effectiveness as a team is not restricted to performing skills geared to instructional intervention. It also involves learning skills needed to become better managers. The inclusion team will be called upon to interact with many individuals. Two areas in which they generally need to improve their skills are time management and assertiveness.

\section{Time Management}

With the reauthorization of IDEA, regulations from the federal and state governments may increase and add to teachers' paperwork. Extra duties that are part of teachers' jobs, such as bus and lunch duty, also have a way of interrupting instructional time (Nelson, 1995). Time management can improve the instructional program in an inclusive classroom, given some basic planning techniques.

Teachers who are going to be part of an inclusion team should seek out resources for learning about time management. Woodhull (1997), Nelson (1995), Lakein (1973), and Applegate (1980) are excellent choices. Teachers in inclusion programs can employ a variety of strategies to improve their effectiveness in using time more productively. These strategies can also be used to teach cooperative learning teams of students.

For example, teachers working in inclusive teams should sort out their professional and personal goals by making team lists. First, the team should list what is to be accomplished during the school year, prioritizing the items from most to least important. Second, the team should develop a daily list of what needs to be accomplished, also by priority.

Another vital aspect of time management for teachers working in inclusive teams is for the team members to organize the schedule, keeping in mind both the classroom and the school in general. Because schools have activities that must be done in preset times, teachers can organize their time around these activities and identify times for uninterrupted work. Also, planning can allow for shortened lessons preceding pep rallies and other school events. Teachers should be flexible when unforeseen interruptions occur, as interruptions are inevitable in schools no matter how good the planning. Before returning to a task, teachers can ask themselves if they should move on to a new task and reschedule the interrupted one.

By identifying the time of the day when the students are most productive, teachers can schedule high-priority tasks for these peak times. One strategy that helps the teachers and the students alike is to keep the schedule fairly constant. The routine of performing a task at roughly the same time each day cuts down on indecision. Once a schedule is set, to cross out the activity upon completion is reinforcing. In addition, a set schedule keeps things moving in the class and reduces procrastination.

Teachers can also battle procrastination through reinforcement. Many people use the Premack principle in reverse, doing something enjoyable first, then working on a less preferred task. Unfortunately, this usually results in procrastination. The goal should be to work first and then get a reward. Also, teachers can task-analyze the activity into smaller chunks, reinforcing themselves after completing each component of the task.

Teaching in inclusive settings can be stressful, and certainly the demands for increased collaboration and coordination between teachers can be tiring. The inclusion team should build into their schedules frequent, short periods when they have nothing to do. Daydreaming can be an effective reinforcer when 
it is controlled. For example, 2 minutes of daydreaming after completing an activity can be an effective impetus for beginning the next task. When teachers sit down to plan an activity, they should set goals that require a specific time or a specific amount of work that must be completed before leaving.

\section{Assertiveness}

When entering into inclusive team arrangements, the need for teachers to develop positive interpersonal skills becomes paramount. The ability to be assertive, rather than aggressive, requires a positive approach in dealing with others. An educator should not be placed in a lower power position than that of the inclusive team member. Nor should inclusive team members be willing to accept the judgments of administrators, psychologists, physicians, or parents that are not based on reciprocity.

How teachers react to attempts at control can result in selfdenying (nonassertive), assertive, or aggressive behaviors. If teachers resort to either self-denying or aggressive behaviors, this can cause others to ignore their good ideas. Several authors, such as Fensterheim and Baer (1975) and Woodhull (1997), have distinguished between assertive and aggressive behavior by defining assertiveness as those traits that allow people to stand up for themselves and make their own choices. Conversely, aggressiveness is an attempt to enhance one's own position at the expense of someone else's rights. In contrast to either of these approaches, nonassertive people allow others to make their decisions and guide their actions, usually at the expense of their own self-esteem (Alberti \& Emmons, 1974; Dyer, 1979). A great deal of stress can be placed on individuals who either continually allow others to dictate to them or alienate colleagues through aggressive actions.

Being assertive allows one to state a point of view or request something in a positive, plain, and strong manner. The key is to make affirmations clearly, based on a well-thought-out set of logical statements. For example, an administrator may inform the inclusive team that five students with disabilities are being introduced into their class without additional support. Accepting this change without question or vehemently arguing against the placement will probably not bring about a satisfactory conclusion. Instead, the team can practice assertive techniques and can calmly but firmly convey to the administrator agreement or disagreement with the finding. The presentation should be supported by data gathered in the classroom.

At times teachers should be assertive and say no. Teachers can't please everyone, so they should be selective of tasks they accept. Administrators, other teachers, and paraprofessionals sometimes transfer their burdens onto the shoulders of others. Instead of agreeing to this, teachers can refer the problem back to these people by saying, "What are you going to do?" or
"What do you think about it?" The skill of delegating authority. Teachers in inclusive programs would do well to develop in situations where additional tasks cannot be refuted, the effective use of paraprofessionals, volunteers, and peer tutors becomes a necessity.

An assertive approach emphasizes on how a person delivers a message to others. Alberti and Emmons (1974) suggested several methods for delivering messages in a positive, yet, assertive manner. For example, using appropriate eye contact (looking directly at people when you are speaking to them) is an effective way of declaring your sincerity about your message. Another suggestion by Alberti and Emmons stresses body posture. They believe that people will take messages more seriously when the message sender faces the person who is to receive the message.

Gestures can accentuate a message if they are appropriate and nonthreatening. Facial expressions also can lead to effective assertions if the expression agrees with the message.

Alberti and Emmons (1974) and more recently, Woodhull (1997) agree that voice tone can be a powerful communicative tool. They provide examples of how level, well modulated, conversational statements are convincing without intimidating or setting off the defenses of another person.

\section{Conflict Resolution and Negotiation}

As the movement toward community-based instruction becomes more popular, the inclusive team will maintain close contact with individuals from many different walks of life. Inevitably, conflict will arise over issues requiring careful negotiation before the program can move forward and benefit the students. When conflicts arise over class placement, for example, arguing differences of opinion can be productive when each side uses facts and does not introduce emotional statements.

Inclusive teams should keep in mind two major points when conflicts arise either with people outside the team or between members of the team:

1. Achieve the team's goals

2. Maintain a good relationship with the other persons involved in the negotiation.

Adhering to these rules should ensure that the appropriate approach is taken in an effort to resolve the conflict to everyone's satisfaction.

When managing interpersonal conflicts, teachers should recognize that conflicts can be settled rationally (Gamble \& Gamble, 1982). Pretending that the conflict does not exist, withdrawing from the conversation, or finding fault or blaming will not facilitate a productive end to the dispute.

The conflict should be defined. Each participant should ask three questions: 
1. Why are we in conflict?

2. What is the nature of the conflict?

3. How can each of us feel as though we have won?

Participants in the conflict should check their perceptions, suggest possible solutions, assess the solutions, decide on the best one, and finally try out the solution, then evaluate its effectiveness.

The key to any successful negotiation is not to approach the discussion with a "must win" attitude (Maddux, 1988). This approach usually results in a no-win situation for all concerned. Teachers who work in inclusion teams should enter conflict situations with a win/win attitude, interested in the needs of others and flexible in their approach to the negotiations at hand.

\section{Technology Solutions and Managing Inclusive Environments}

A variety of technology solutions can help teachers who work in inclusive programs to become more effective in managing the instructional environment (Howell, 1996). For example, computer-managed instruction (CMI) helps teachers become more efficient in handling the daily paperwork and record keeping inherent in their roles. In addition, CMI can assist teachers in developing IEPs and monitoring student progress, as well as diagnosing and assessing students' strengths and weaknesses.

Computer-based word-processing programs can be helpful in a number of ways.

- They can facilitate a teacher's communications with parents and other professionals.

- They can provide an efficient mechanism for storing, filing, and retrieving data.

- Teachers can generate letters and forms that require frequent changes (dates, places) with little effort.

- Teachers can quickly enter information such as class lists and schedules and easily edit them when necessary.

- Word-processing programs can be of tremendous help in collating and storing data obtained for assessment. Information relevant to all curricular domains can easily be entered and stored.

- Teachers can use these programs to list instructional objectives by curriculum area for retrieval during the development of IEPs.

One way for the inclusion team to optimize planning time is to use one of the computer-generated IEP programs available commercially. These programs allow teachers to pull objectives from a list and transfer them to a template form of the IEP.
These objectives are often keyed to a specific standardized or criterion-referenced assessment device. When teachers enter the student's data, the program will retrieve precoded objectives based on the student's assessment profile. When used correctly, computer-generated IEPs can be efficient and effective tools that can improve the overall quality of IEPs.

Data-based instruction has long been the goal of special educators. With the advancement of computer-based monitoring programs, this task becomes much easier. Computer-based monitoring programs allow teachers to store, graph, and analyze academic, social/emotional, and other behaviors of students (Hasselbring \& Goin, 1989; Stephens, Blackhurst, \& Magliocca, 1988).

Hasselbring and Hamlett (1984) developed a computerbased monitoring program called AIMSTAR. This program allows teachers to develop student data files that include information about the instructional program and store performance data relating to a student's program. For example, an inclusion team could store a student's performance data on the number of correct cost-comparison shopping problems he or she solved. The teachers could include in the data file the amount of time the student took to complete the task. When needed, the program would generate a graphic representation of progress, depicting it in rate or movements per minute. The AIMSTAR program assists teachers by recommending changes in the program when appropriate.

In addition to their use in monitoring student progress, computers can be used earlier in program development to assist professionals in diagnosing and assessing students' strengths and weaknesses (Lick \& Little, 1987). Computer programs are now available to assist in the scoring and analysis of many standardized tests. In addition, some programs allow students to take the test directly on the computer with little assistance from professionals. These programs offer the potential of minimizing some of the time-consuming tasks required of special educators and allowing them to spend more time in teaching and instructional development.

Computer-assisted management can help teachers working in inclusive teams improve their service to all students. CAM programs can be of great assistance in the accountability requirements of federal, state, and local agencies (Levy \& Lahm, 1985; McClellan, 1985). These programs provide the means to store, organize, and use large quantities of data for decision-making purposes in a highly cost-effective manner (Marozas \& May, 1988). For example, some software programs assist in scheduling, grading, managing grants and projects, establishing student tracking systems, writing budgets and financial reports, and a host of other effective and efficient management approaches. 


\section{CONCLUSION}

The growth of inclusive instructional settings requires teachers to meet new organizational demands while still fulfilling more traditional duties. Inclusionary programs have to be developed and implemented with the input of all team members. This requires cooperative planning and team-based organization, as well as the individual strengths and expertise of each team member. Components such as the physical arrangement of the room, scheduling, responsibilities of each adult, and use of technology must be considered for each activity. Fortunately, as inclusionary classrooms become more common, research and sources of information for support and methods for teachers who work as inclusive teams will become more widely available.

\section{REFERENCES}

Alberti, R. E., \& Emmons, M. L. (1974). Your perfect right: A guide to assertive behavior. San Luis Obispo, CA: Impact.

Applegate, J. (1980). Time. In D. R. Cruickshank (Ed.), Teaching is tough (pp. 257-300). Englewood Cliffs, NJ: Prentice Hall.

Braaten, S., Kauffman, J. M., Braaten, B., Polsgrove, L., \& Nelson, C. M. (1988). The regular education initiative: Patent medicine for behavior disorders. Exceptional Children, 55, 21-27.

Brown, J. S., Collins, A., \& Duguid, P. (1989). Situated cognition and the culture of learning. Educational Researcher, 18, 32-41.

Bryan, T., Bay, M., \& Donahue, M. (1988). Identifications of the learning disabilities definition for the regular education initiative. Journal of Learning Disabilities, 21, 23-28.

Cartledge, G., \& Johnson, C. T. (1996). Inclusive classrooms for students with emotional and behavioral disorders: Critical variables. Theory Into Practice, 35, 51-57.

Cipani, E. (1995). Inclusive education: What do we know and what do we still have to learn? Exceptional Children, 61, 498-500.

Cognition and Technology Group at Vanderbilt. (1990). Anchored instruction and its relationship to situated cognition. Educational Researcher, 19(6), 2-10.

Cognition and Technology Group at Vanderbilt. (1993). Anchored instruction and situated cognition revisited. Educational Technology, 33(3), 52-70.

Cook, L., \& Friend, M. (1996). Co-teaching: Guidelines for creating effective practices. In E. L. Meyen, G. A. Vergason, \& R. J. Whelan (Eds.), Strategies for teaching exceptional children in inclusive settings. Denver: Love Publishing.

Danielson, L. C., \& Malouf, D. B. (1994). In J. E. Ysseldyke, \& M. L. Thurlow, (Eds.), Educational outcomes for students with disabilities (pp. 11-19). Binghamton, NY: Haworth Press.

Davis, W. E. (1989). The regular educative initiative devate: Its promises and problems. Exceptional Children, 55, 440-446.

Dyer, W. (1979). Pulling your own strings. New York: Avon.

Edgar, E. (1987). Secondary programs in special education: Are many of them justifiable? Exceptional Children, 53, 555-556.
Eichinger, J., \& Woltman, S. (1993). Integration strategies for learners with severe multiple disabilities. Teaching Exceptional Children, 26(1), 18-21.

Falvey, M (1995). Inclusive and heterogeneous schooling: Assessment, curriculum, and instruction. Baltimore: Paul Brookes Publishing.

Farber, B. (Ed.). (1991). Crisis in education: Stress and burnout in the American teacher. San Francisco: Jossey-Bass.

Fensterheim, H., \& Baer, J. (1975). Don't say yes when you want to say no. New York: David McKay.

Fisher, J. B., Schumaker, J. B., \& Deshler, D. D. (1996). Searching for validated inclusive practices: A review of the literature. In E. L. Meyen, G. A. Vergason, \& R. J. Whelan (Eds.), Strategies for teaching exceptional children in inclusive settings. Denver: Love Publishing.

Frank, A., \& McKenzie, R. (1993). The development of burnout among special educators. Teacher Education and Special Education, 16, 161-170.

Fuchs, D., \& Fuchs, L. (1988a). Evaluation of the adaptive learning environments model. Exceptional Children, 55, 115-127.

Fuchs, D., \& Fuchs, L. (1988b). Response to Wang and Wahlberg. Exceptional Children, 55, 138-145.

Fuchs, D., \& Fuchs, L. (1994). Inclusive schools movement and the radicalization of special education. Exceptional Children, 60 , 294-309.

Gamble, T. K., \& Gamble, M. (1982). Contacts: Communicating interpersonally. New York: Random House.

Griffin, M. M. (1995). You can't get there from here: Situated learning, transfer, and map skills. Contemporary Educational Psychology, 20, 65-87.

Hallahan, D. P., Keller, C. E., McKinney, J. D., Lloyd, J. W., \& Bryan, T. (1988). Examining the research base of the regular education initiative: Efficiency studies and the adaptive learning environments model. Journal of Learning Disabilities, 21, $29-35,55$.

Hart, V. (1981). Mainstreaming children with special needs. New York: Longman.

Hasselbring, T., \& Goin, L. I. (1989). Enhancing learning through microcomputer technology. In E. A. Polloway, J. R. Patton, J. S. Payne, \& R. A. Payne (Eds.), Strategies for teachers with learners with special needs (4th ed., pp. 147-164). Columbus, $\mathrm{OH}$ : Charles E. Merrill.

Hasselbring, T., \& Hamlett, C. (1984). AIMSTAR. Portland, OR: ASIEP Education.

Hedberg, J., \& Alexander, S. (1994). Virtual reality in education: Defining researchable issues. Educational Media International, 31, 214-220.

Heller, K., Holtzman, W., \& Messick, S. (Eds.). (1982). Placing children in special education: A strategy for equity. Washington, DC: National Academy Press.

Howell, R. (1996). Technological aids for inclusive classrooms. Theory Into Practice, 35, 58-65.

Hughes, C., \& Agran, M. (1993). Teaching persons with severe disabilities to use self-instruction in community settings: An anal- 
ysis of applications. Journal of the Association of Persons with Severe Handicaps, 18, 261-273.

Janney, R. E., Snell, M. E., Beers, M. K., \& Raynes, M. (1995). Integrating students with moderate and severe disabilities into general education classes. Exceptional Children, 61, 425-439.

Jenkins, J. R., Pious, C. G., \& Jewell, M. (1990). Special education and the regular education initiative: Basic assumptions. Exceptional Children, 56, 479-491.

Kauffman, J. M., Gerber, M. M., \& Semmel, M. I. (1988). Arguable assumption underlying the regular education initiative. Journal of Learning Disabilities, 21, 6-11.

Keogh, B. K. (1988). Improving services for problem learners: Rethinking and restructuring. Journal of Learning Disabilities, 21, 19-22.

Lakein, A. (1973). How to get control of your time and your life. New York: P. H. Wyden.

Langone, J. (1990). Teaching students with mild and moderate learning problems. Boston: Allyn and Bacon.

Langone, J. (1996). Mild mental retardation. In P. J. McLaughlin \& P. Wehman (eds.), Mental retardation and developmental disabilities (2nd. Ed). Austin, TX: PRO-ED.

Lave, J. (1988). Cognition in practice: Mind, mathematics and culture in everyday life. Cambridge, MA: Cambridge University Press.

Levy, S. A., \& Lahm, E. A. (1985). Microcomputers in special education management. In E. McClellan (Ed.), Microcomputer applications in special education: A training manual for special education teacher educators. Reston, VA:

Council for Exceptional Children.

Lick, C. M., \& Little, T. H. (1987). Computers and mildly handicapped individuals. In J. D. Lindsey (Ed.), Computers and exceptional individuals (pp. 61-82). Columbus, OH: Charles E. Merrill.

Maddux, R. B. (1988). Successful negotiation. Los Altos, CA: Crisp Publications.

Marozas, D. S., \& May, D. C. (1988). Issues and practices in special education. New York: Longman.

McClellan, E. (1985). Introduction to microcomputers. In E. McClellan (Ed.), Microcomputer applications in special education: A training manual for special education teacher educators (pp. I-1-I-14). Reston, VA: Council for Exceptional Children.
McDonnell, J., Hardman, M.L., Hightower, J., Keifer-O’ Donnell, \& Drew, C. (1993). Impact of community-based instruction on the development of adaptive behavior of secondary-level students with mental retardation. American Journal on Mental Retardation, 97, 575-584.

McNulty, B. A., Connolly, T. R., Wilson, P. G., \& Brewer, R. D. (1996). LRE policy: The leadership challenge. Remedial \& Special Education, 17, 158-167.

Nelson, I. (1995). Time management for teachers. London: Kogan Page Ltd.

Nolet, V., \& Tindal, G. (1996). Curriculum-based collaboration. In E. L. Meyen, G. A. Vergason, \& R. J. Whelan (Eds.), Strategies for teaching exceptional children in inclusive settings. Denver: Love Publishing.

Polloway, E. A., \& Smith, J. D. (1983). Changes in mild mental retardation: Population, programs, and perspectives. Exceptional Children, 50, 149.

Pugach, M., \& Johnson, L. (1995). Collaborative practitioners, collaborative schools. Denver: Love Publishing.

Rekkas, A. (1997). Strategies for inclusion: An annotated bibliography. Childhood Education: Infancy Through Early Adolescence, 73, 168-171.

Reynolds, M. C. (1988). A reaction to the JLD special series on the regular education initiative. Journal of Learning Disabilities, 21, 352-356.

Reynolds, M. C., Wang, M. C., \& Wahlberg, H. J. (1987). The necessary restructuring of special and regular education. Exceptional Children, 53, 391-398.

Rock, E. E., Rosenberg, M. S., \& Carran, D. T. (1995). Variables affecting the reintegration rate of students with serious emotional disturbance. Exceptional Children, 61, 254-268.

Scruggs, T. E., \& Mastropieri, M. A. (1996). Teacher perceptions of mainstreaming/inclusion, 1958-1995: A research synthesis. Exceptional Children, 63, 59-74.

Shriner, J. G. (1994). Broadening educational outcomes beyond academics. In J. E. Ysseldyke, \& M. L. Thurlow, (Eds.). Educational outcomes for students with disabilities (pp. 139-154). Binghamton, NY: Haworth Press.

Snell, M., \& Browder, D. M. (1986). Community-referenced instruction:Research and issues. Journal of the Association for Persons with Severe Handicaps, 11, 1-11.

\section{PERMISSIONS AND COPYRIGHT}

All rights are reserved. No part of this publication may be reproduced, photocopied, faxed, stored in a retrieval system, or transmitted, in any form or by any means, electronic, mechanical, recording or otherwise, without the prior written permission of the publisher.
Back issues are available for sale. Reproduction requires permission and payment of fees. It is illegal and a violation of federal copyright law to reproduce this publication without permission. Direct all inquiries to the permissions editor. 
Stainback, S., Stainback, W. (1992). Curriculum considerations in inclusive schools: Facilitating learning in all students. Baltimore: Paul H. Brookes.

Stainback, W., \& Stainback, S. (1984). A rationale for the merger of special and regular education. Exceptional Children, 51, 102-111.

Stainback, W., Stainback, S. (Eds.) (1996). Inclusion: A guide for educators. Baltimore: Paul H. Brookes.

Stainback, W., Stainback, S., \& Stefanich, G. (1996). Learning together in inclusive classrooms: What about curriculum? Teaching Exceptional Children, 28(3), 14-19.

Stephens, T. M., Blackhurst, A. E., \& Magliocca, L. A. (1988). Teaching mainstreamed students ( $2 \mathrm{~d}$ ed.). New York: Pergamon Press.

Tripp, S. D. (1993). Theories, traditions, and situated learning. Educational Technology, 33(3), 71-77.

Vaughn, S., Bos, C. S., \& Schumm, J. S. (1997). Teaching mainstreamed, diverse, and at-risk students in the general education classroom. Boston: Allyn and Bacon.

Villa, R. A., Thousand, J. S., \& Chapple, J. W. (1996). Preparing teachers to support inclusion: Preservice and inservice programs. Theory Into Practice, 35, 42-50.

Villa, R. A., Thousand, J. S., Meyers, H., \& Nevin, A. (1996). Teacher and administrator perceptions of hetrogeneous education. Exceptional Children, 63, 29-46.
Voltz, D., Elliott, R., \& Cobb, H. (1994). Collaborative teacher roles: Special and general educators. Journal of Learning Disabilities, 27, 527-535.

Wang, M. C. \& Walberg, H.J. (1988). Four fallacies of segregationism. Exceptional Children, 55,128-137.

Warger, C. D., \& Pugach, M. C. (1996). Curriculum considerations in an inclusive environment. In E. L. Meyen, G. A. Vergason, \& R. J. Whelan (Eds.), Strategies for teaching exceptional children in inclusive settings. Denver: Love Publishing.

Williams, W., \& Fox, T. J. (1996). Planning for inclusion: A practical process. Teaching Exceptional Children, 28(3), 6-13.

Whitehead, A. N. (1929). The aims of education. New York: Macmillan.

Wolfe, P. S. (1994). Judgment of the social validity of instructional strategies used in community-based instructional sites. Journal of the Association of Persons with Severe Handicaps, 19 , 43-51.

Woodhull, A. V. (1997). The new time manager. Hampshire, England: Gower Publishing.

Young, M. F. (1993). Instructional design for situated learning. Educational Technology Research and Development, 41, 43-58. 


\section{Professional update}

\section{National Association of School Psychologists}

April 14-18, 1998

Annual Conference

Orlando, FL

Contact: National Association of School Psychologists 4340 East West Highway

Suite 402

Bethesda, MD 20814

\section{Council for Exceptional Children}

April 15-19, 1998

Annual Conference

Minneapolis, MN

Contact: Council for Exceptional Children 1920 Association Drive Reston, VA 22091

\section{Reminder: Deadline coming soon \\ Call for Proposals for the IASE Sixth Biennial International Conference}

The International Association of Special Education will hold their 6th Biennial Conference at the University of Sydney, in New South Wales, Australia 19-23 July 1999. The theme is

"Overcoming Great Barriers: Meeting the Needs of Individuals with Disabilities."

Topics areas include, Classroom Instruction, Curriculum, Assessment Procedures, Vocational, Funding/Grant Writing, Inclusionary Best Practices, Multicultural Perspectives, Staff Development, Early Childhood, Technology, Program Development, Art/Music/Physical Education, Service Delivery Systems, and Policies and Politics.

Proposals must be received by 15 October 1998, and must be submitted in English. Evaluation by an international review team will be based on clarity and organization, content relevant to educational and cultural practices, systems of service delivery and the future development of these practices at national and international levels. Applicants will be notified of acceptance by 1 December 1998.

For more information regarding submitting a proposal, write: Dr. Susan Butler, IASE Conference, Univ. of Sydney Faculty of Education, Bldg A-35 Sydney, NSW 2006 Australia

To be placed on the mailing list for more information concerning the conference and pre- and post-conference study/travel tours contact:

IASE, Post Office Box 291 